\title{
IMPLEMENTASI STRATEGI STP (SEGMENTATION, TARGETING \& POSITIONING) DI DESA WISATA RUMAH DOME, SLEMAN, YOGYAKARTA
}

\author{
Nurlena $^{1}$, Musadad $^{2}$, Ratu Ratna ${ }^{3}$ \\ ${ }^{I}$ Prodi D3 Perhotelan, Universitas Telkom, Bandung, \\ nurlena@tass.telkomuniversity.ac.id \\ ${ }^{2}$ Prodi Usaha Perjalanan Wisata, Universitas Riau, Pekanbaru \\ sadad.sanusi@gmail.com
}

\begin{abstract}
ABSTRAK
Akibat gempa bumi yang terjadi pada tahun 2006 di Bantul, Yogyakarta, penduduk Desa Nglepen, Kabupaten Sleman harus dipindahkan ke tempat yang lebih aman dengan dibuatkan rumah-rumah berbentuk kubah (dome) untuk mereka tinggali. Lambat laun, karena keunikannya, warga mengubah kompleks rumah dome tersebut menjadi obejek wisata (desa wisata). Mereka mulai melakukan kegiatan pemasaran akan tetapi jumlah pengunjung tetap rendah. Oleh karena itu, artikel ini berusaha mendeskripsikan implementasi kegiatan pemasaran yang ada dengan menggunakan analisis strategi STP (segmentation, targeting, \& positioning).
\end{abstract}

Kata kunci:strategi pemasaran, desa wisata, rumah dome

\section{ABSTRACT}

Due to the earthquake occurred in 2006 in Bantul, Yogyakarta, the residents of Nglepen Village, Sleman Regency had to be relocated to a safer place in which dome-shaped houses were built for their new houses. Gradually, due to its uniqueness, the residents turned the dome complex into a tourist destination (tourist village). They began doing marketing activities but the number of visitors remained low. This paper, therefore, seeks to investigate the implementation of the existing marketing activities by employingthe analysis of the segmentation, targeting, and positioning strategy.

Keywords:marketing strategy, tourist village, dome houses

\section{PENDAHULUAN}

Akibat gempat yang terjadi pada tahun 2006, Desa Nglepen yang terletak di Kabupaten Sleman akhirnya direlokasi ke bawah bukit agar lebih aman. Dengan bantuan World Association of Non-GovernmentalOrganizations (WANGO) yang meminta bantuan Domes for the World Foundation (DTWF), akhirnya dibangunlah rumah-rumah berbentuk dome untuk pemukiman warga.Rumah-rumah dome ini diklaim lebih permanen, ekonomis, dan tahan gempa. Area pemukiman dome yangdidesain secara rapi dan teratur menimbulkan kesan bangunan berasitektural indah dan berseni. 


\section{National Conference of Creative Industry: Sustainable Tourism Industry for Economic Development}

Universitas Bunda Mulia, Jakarta, 5-6 September 2018 ISSN No: 2622-7436

Lambat laun, rumah dome juga berfungsi sebagai objek wisata. Jadi,desa ini berfungsi sebagai tempat tinggal sekaligus tempat wisata. Peralihan menjadi objek wisata ini erat kaitannya dengan gencarnya program-program kepariwisataan di Daerah Istimewa Yogyakarta, khususnya Kabupaten Sleman.

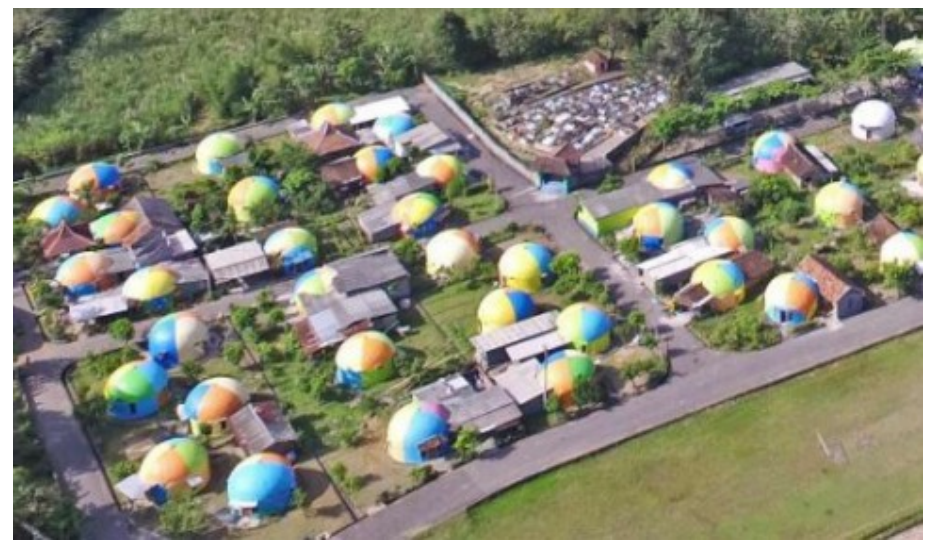

Gambar 1. Desa Wisata Rumah Dome dilihat dari atas

Sumber: viva.co.id

Ketika dicanangkan menjadi desa wisata dengan atraksi yang unik inilah muncul strategi pemasaran. Dengan mengusung tema "Rumah Teletubbies", desa wisata rumah dome mulai menjalankan aktifitas pemasaran dengan menarget segmen pasar anakanak. Akan tetapi berbagai masalah mulai menghampiri dengan sedikitnya pengunjung yang datang. Oleh karena itu,artikel ini memaparkanpenerapan strategi pemasaran yang ada (existing) dengan menggunakan analisissegmentation, targeting, and positioning (STP).

\section{TINJAUAN PUSTAKA}

\section{Desa Wisata}

Desa wisata adalah suatu bentuk integrasi antara atraksi, akomodasi dan fasilitas pendukung yang disajikan dalam suatu struktur kehidupan masyarakat yang menyatu dengan tata cara dan tradisi yang berlaku. Di dalam Proceedings onUniversal Tourism: Enriching or Degrading Culture?, Nuryanti (1993)mengklaim terdapat dua konsep yang utama dalam komponen desa wisata:

a. Akomodasi: sebagian dari tern pat tinggal para penduduksetempat dan atau unit-unit yang berkembang atas konsep tempat tinggal penduduk.

b. Atraksi: seluruh kehidupan keseharian penduduk setempat beserta setting fisik lokasi desa yang memungkinkan berintegrasinya wisatawan sebagai partisipasi aktif seperti: kursustari, bahasa dan Iain-Iain yang spesifik.

Sedangkan Inskeep (1991:166), dalam Tourism Planning: An integrated and Sustainable Development Approach, memberikan definisi: Village Tourism, where small groups of tourist stay in or near traditional, often remote villages and learn about village life and the local environment. " Wisata pedesaan dimana sekelompok kecil wisatawan tinggal dalam atau dekat dengan suasana tradisional, sering di desa-desa yang terpencil dan belajar tentang kehidupan pedesaan dan lingkungan setempat". 


\section{National Conference of Creative Industry: Sustainable Tourism Industry for Economic Development}

Universitas Bunda Mulia, Jakarta, 5-6 September 2018

ISSN No: 2622-7436

Sementara itu, menurut Muliawan (2008) mengatakan kriteria sebuah desa wisata adalah desa yang memiliki potensi daya tarik wisata dan keunikan yang khas, dikemas dan dikelola secara alami dan menarik dengan pengembangan fasilitas pendukung wisatanya, serta mampu menggerakkan kegiatan ekonomi yang berujung pada peningkatan kemakmuranwargalokal.

Terkait dengam isu desa wisata diatas, Nuryanti (1993) mengatakan bahwa "village tourism has to be economically feasible to offer a viable alternative." Dari pernyataan tersebut, desa wisata mampu menjadi sebuah alternatif dalam kaitannya dengan peningkatan ekonomi warga masyarakat karena desa wisata mampu memberikan kontribusi langsung terhadap peduduk lokal "it is structured to benefit the local community directly” (Nuryanti, 1993).

\section{Segmentation, Targeting, \& Positioning}

Smith dalam Angipora (2002) mengemukakan bahwa segmentasi pasar merupakan pembagian dari pasar secara keseluruhan dalam kelompok-kelompok sesuai dengan kebutuhan dan ciri-ciri konsumen. Salah satu cara yang dapat digunakan dalam membentuk segmentasi pasar adalah mengidentifikasi kelompok pembeli (Kotler, 2005). Segmentasi memungkinkan organisasi jasa mampu menyesuaikan teknis penawaran, operasi atau penggunaan jasa (pelayanan) yang lebih baik. Terdapat empat pembagian pasar menurut Kotler (2005) yakni geografi, demografi, serta psikografis.

Setelah melaksanakan segmentation, selanjutnya dilakukan targeting. Targetting merupakan kegiatan yang berisi dan menilai serta memilih satu dari segmen pasar yang akan dimasuki oleh suatu perusahaan. Dalam memilih segmen mana yang dijadikan sasaran, perusahaan dapat memilih untuk memusatkan perhatian pada satu segmen, beberapa segmen, produk spesifik, pasar yang spesifik atau seluruh pasar (Kotler, 2005). Dalam memilih pangsa pasar sasaran, perusahaan harus memperhatikan tanggung jawab sosial dan tidak semata-mata untuk mencari kepentingan perusahaan tetapi tetap memperhatikan kepentingan mereka yang dijadikan sasaran.Disini sebuah perusahaan harus mengevaluasi daya tarik masing-masing segmen serta memilih segmen-segmen sasaran.

Positioning adalah tindakan merancang tawaran dan citra perusahaan sehingga menempati suatu posisi yang terbedakan (diantara pesaing) didalam benak pelanggan sasarannya (Kotler, 2005). Hasil akhir dari positioning adalah keberhasilan penciptaan suatu usulan nilai yang terfokus pada pasar. Positioning yang efektif mensyaratkan bahwa suatu perusahaan menyadari dan mengekploitasi kelemahan-kelemahan pesaingnya.Dalam positioning,sebuah perushaan harus mengidentifikasi konsep positioning yang memungkinkan bagi masing-masing segmen sasaran serta memilih, mengembangkan, dan mengkomunikasikan konsep posisioning yang dipilih(Kotler, 2005).

\section{METODE PENELITIAN}

Penelitian ini menggunakan pendekatan deskriptif kualitatif. Jadi, penelitian ini adalah penelitian eksploratif karena berusaha untuk mengeksplorasi masalah dengan bantuan informan. Data dikumpulkan melalui wawancara, studi pustaka, dan observasi. Wawancara dilakukan dengan informan seperti masyarakat setempat dan staf dinas pariwisata. Studi literatur juga dilakukan untuk mengeksplorasi data sekunder terkait 


\section{National Conference of Creative Industry: Sustainable Tourism Industry for Economic Development}

Universitas Bunda Mulia, Jakarta, 5-6 September 2018 ISSN No: 2622-7436

penelitian seperti dokumen desa, koran, atau dokumen lainnya. Observasi secara langsung dilakukan untuk menemukan potensi wisata (3A) termasuk atraksi, amenitas, dan aksesibilitas.

Analisis data dilakukan secara induktif, mulai dari lapangan atau fakta empiris dengan mengunjungi langsung ke lapangan, dan mempelajari fenomena di lapangan. Karena menggunakan penalaran induktif, perumusan hipotesis tidak diperlukan. Berikut ini adalah tahap analisis induktif menurut Nasution (1988) meliputi data reduction, data display, dan conclusion atau verivication. Di dalam data display, dilakukan narrative analysis dan SWOT analysis.

\section{HASIL PENELITIAN DAN PEMBAHASAN}

\section{Analisis 3 A Desa Wisata Rumah Dome}

Rumah Dome merupakan suatu bentuk rumah yang unik. Bentuknya kubah atau bulat yang lebih dikenal dengan nama rumah teletubies. Bentuk rumah ini baru pertama kali ada di Indonesia bahkan se-Asia, tempat ini merupakan bangunan anti gempa, anti kebakaran dan anti badai pasang.

Rumah Dome terletak di Dusun Sengir, Sumberharjo, Prambanan, Sleman yang dibangun oleh WANGO (World Association of NGO's atau asosiasi lembaga non pemerintah se dunia) dan Domes For The World.Ragam Obyek Wisata Domes diantaranya adalah Rumah Domes, Tanah Ambles, Candi Kerajinan, Belik Wunut. Terkait dengan 3Adi rumah dome, berikut adalah penjabarannya:

1. Atraksi

Desa Wisata Rumah Dome sebenarnya sudah mempunyai paket wisata. Terdapat tiga paket wisata yang ditawarkan yaitu Paket Matahari (Rp 10.000,- per orang), Paket Pelangi (Rp 15.000,- per orang) dan Paket Hiburan (Rp 200.000). Wisatawan tinggal memilih paket mana yang seuai dengan minat dan budget mereka. Dari sekian atraksi yang ditawarkan, sebenarnya desa wisata ini memiliki keunikan dan karakter sendiri yang sangat potensial tetapi pengunjung tetap sedikit.

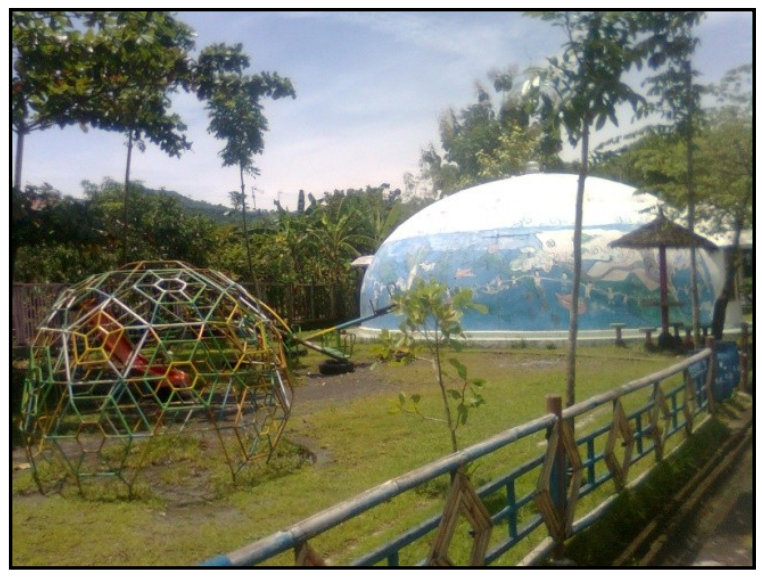

Gambar 2. Tempat bermain anak

Sumber: Dokumentasi Pribadi

Berdasarkan pengakuan salah satu pengelola, Mas Sakiran, desa wisata ini juga menyediakan permainan anak-anak. Segala macam permainan tradisional dapat 


\section{National Conference of Creative Industry: Sustainable Tourism Industry for Economic Development}

Universitas Bunda Mulia, Jakarta, 5-6 September 2018

ISSN No: 2622-7436

ditemukan di sini. Menurut pengelola nantinya akan dikembangakan dengan mandi bola, kereta listrik, sepeda unik serta pemancingan anak-anak. Lahan parkir juga disediakan, dengan tarif $\mathrm{Rp} 500$ untuk sepeda, Rp 1,000 untuk sepeda motor serta mobil sebesar Rp 2.000. Sebelum meninggalkan lokasi wisata, anda juga bisa membeli oleholeh berupa souvenir miniatur Rumah Dome seharga Rp 10.000, gantungan kunci Rp 10 ribu, kaos bergambar Rumah Dome Rp 35.000 sampai Rp 40.000. Sedangkan mug Rp 2.000. Selain itu anda juga dapat membeli CD rekaman tentang tanah yang amblas, diambil setelah peristiwa gempa, seharga Rp 10.000.

2. Amenitas

Dalam usahanya sebagai desa wisata, perumahan Dome diberi banyak fasilitas misalkantempat informasi, mushola, klinik, area bermain, kamar mandi, tempat rapat, serta kios yang menjual aneka jajanan dan cendera mata. Mereka yang hendakmemakai aula meeting untuk hajatan dan lain-lain dikenakan biayaRp 30.000,00 belum termasuk konsumsi.Sementara itu, pengunjung yang tertarik tinggal di Rumah Dome bisa membayar paket menginap (homestay). Biaya yang dikenakan adalah Rp. 55 ribu per orang dan ini sudah lengkap dengan makan tiga kali. Tidak hanya itu, terdapat juga paket seni dan budaya. Bagi wisatawan yang tertarik menyaksikan atraksi seni, mereka dapat memesan kepada pengelola dengan membayar Rp 200.000,-. Ada beberapa seni pertunjukan tradisional disini seperti Karawitan, organ tunggal, dan Tek-Tek,.

3. Aksesibilitas

Pada intinya, akses ke kompleks Rumah Dome sangat mudah. Hal ini karena lokasinya yang dekat dengan jalan raya. Apalagi, kompleks ini letaknya tidak begitu jauh dari kompleks Candi Prambanan dan Candi Ratu Boko. Letaknya yang berdekatan dengan objek wisatawa terkenal seperi Prambanan dan Ratu Boko ini sebenarnya menjadi potensi yang baik bagi pengembangan komplek Rumah Dome dalam menarik wisatawan untuk datang. Semua kendaraan bisa masuk, termasuk Bus Pariwisata. Bagi wisatawan yang menuju kompleks Rumah Dome dari Yogyakarta, terdapat dua jalur, yaitu lewat jalan lewat jalan Solo-Yogyakarta lalu belok ke kiri ke arah Piyungan. Sedangkan jalur kedua dapat lewat jalan Jogja-Wonosari, lalu belok ke kiri. Sudah terdapat penjunjuk arah, sehingga wisatawan tidak perlu kerepotan mencari lokasinya.

\section{Strategi Pemasaran Yang Telah Ada (Existing)}

Selama ini, strategi pemasaran yang telah ada dilakukan dengan menciptakan brand image rumah dome sebagai atraksi wisata anak-anak. Salah satu hal yang dibangun adalah mengusung tema teletubbies. Hal ini dilakukan karena bentuk rumah bulat mengingatkan kepada sebuah acara anak-anak teletubbies. Akan tetapi dari sumber yang ada mengatakan bahwa promosi dan pemasaran masih sangat terbatas. Mereka lebih focus menggunakan dana yang ada untuk membagun fasilitas-fasilitas/wahana-wahana tanpa mengimbangi dengan strategi pemasaran yang memadai. Untuk itulah strategi pemasaran perlu segera dilakukan, salah satunya adalah dengan mengusung strategi segmentation, targeting, and positioning.

1. Segmentation

Menurut Kotler (2005), variabel-variabel yang dapat digunakan untuk mensegmentasikan pasar terdiri dari segmentasi geografis, demografis, psikografis dan perilaku.

a. Demografis

Penyediaan obyek dan atraksi wisata (supply) harus ada komplementarisasi/kesesuaian dengan pasar pariwisata (demand). Selain yang 


\section{National Conference of Creative Industry: Sustainable Tourism Industry for Economic Development}

Universitas Bunda Mulia, Jakarta, 5-6 September 2018

ISSN No: 2622-7436

sudah di sebutkan di atas hal yang tidak kalah pentingnya dalam segmentasi pasar adalah faktor usia wisatawan, karena faktor usia berpengaruh terhadap pola pikir dan pandangan mereka terhadap jenis wisata yang dipilih. Usia disini dipilih mereka yang masih dalam kelompok usia bermain (4-12 tahun). Selain anak-anak, pasar keluarga juga sangat memungkinakan untuk didatangkan. Dengan menusung tema refreshing bersama keluarga rumah dome bisa ditawarkan kepada mereka yang ingin berjalan-jalan, berrekreasi bersama keluarga tercinta. Jadi tidak hanya menyasar sekolah-sekolah.

b. Psikografis

Segmentasi secara perilaku menggolongkan wisatawan berdasarkan kesamaan pengetahuan, sikap, tingkat penggunaan, maupun respons terhadap suatu produk. Contoh dasar penggolongan yang biasa digunakan adalah 'waktu konsumsi/melalukan perjalanan', yaitu misalnya saat perayaan Idul Fitri banyak daerah yang dikunjungi pemudik dari kota lain dan ada daya tarik wisata (misalnya: pantai dan kebun binatang) yang secara tradisional dikunjungi. Segmentasi berdasarkan frekuensi perjalanan termasuk dalam segmentasi perilaku, sementara manfaat (benefit segmentation) sering dimasukkan dalam baik segmentasi secara perilaku maupun segmentasi psikografis.

Disini mereka yang terikat dengan gempa bantul 2006 bisa dijadikan salahsatu segmen psokografis. Mereka adalah orang-ornag yang mempunyai kenangan terhadap gempa, sehingga kehadiran rumah dome bisa menjadi salah satu media mereka mengenang masa lalu itu untuk selanjutnya menatap masa depan dengan melihat rumah perkasa dan kuat.

Selain mereka yang punya kenangan dengan gempa 2006, mereka yang kecapekan/kelelahan/penat dengan aktifitas perjalanan wisata (katakanlah habis muter-muter candi prambanan dan candi ratu boko) maka rumah dome bisa menjadi tempat peristirahatan sementara, untuk refresehing dan sebagainya. Terkait dengan hal ini, kalangan para pekerja di kantor-kantor di kota-kota seperti Yogyakarta juga bisa ditawri untuk berkunjung melepas lelah di rumah dome pada hari weekend bersama keluarga terntunya.

c. Geografis

Segmentasi secara geografis berarti pembagian wisatawan ke dalam kelompokkelompok berdasarkan unit geografis, seperti asal negara, provinsi, kota, atau wilayah tertentu. Dasar segmentasi ini mengasumsikan bahwa proksimitas (kedekatan wilayah) berperan penting dalam pengambilan keputusan. Kedekatan wilayah menyebabkan kesamaan selera dan kemudahan akses ke penyedia jasa. Untuk wisatawan mancanegara, karakteristik negara asal seringkali cukup kuat sebagai faktor pembeda antara wisatawan dari suatu negara dari negara lainnya.

Walaupun rumah dome sudah dikunjungi oleh wisatwan mancanegara, namun potensi utama wisatawan adalah masyarakat lokal dengan tema "rumah teletubbies" dan wisata keluarganya. Oleh karena itu, untuk segmen wisatwan luarnegri jangan terlalu dikejar dulu. Fokus dulu pada pasar dalam negri. Lebih sempit lagi adalah mereka yang tinggal di wilayah Yogyakarta pada umumnya, Sleman, Kalten, dan Wonosari pada khususnya mengingat lokasi yang dekat dengan ketiga daerah tersebut.

\section{Targeting}

Pasar yang sangat potensial untuk disasar adalah anak-anak mulai play group sampai SD. Anak-anak di usia ini tergolong kelompok usia bermain (usia 4-12 tahun), 


\section{National Conference of Creative Industry: Sustainable Tourism Industry for Economic Development}

Universitas Bunda Mulia, Jakarta, 5-6 September 2018

ISSN No: 2622-7436

berbeda dengan SMP ke atas dimana mereka mulai serius belajar dan sudah agak dewasa. Oleh karenanya, promosi perlu dilakukan kepada sekolah-sekolah, terutama yang berada di seputaran Prambanan dan daerah Bantul timur. Tetapi tidak menutup kemungkinan untuk menyebarkan sayap hingga ke Yogyakarta, klaten, bahkan Gunung Kidul mengingat lokasi rumah dome dekat dengan ketiga daerah tersebut.

Selain menjaring segmen anak-anak, segmen orange dewasa terutama mahasiswa juga berpotensi untuk dilakukan, bahkan wisatawan secara umum. Artinya mereka yang jenuh dengan wisata alam, purbakala, teknologi, dsb. Mereka bisa mencicipi nuansa baru wisata yang ditawarkan rumah unik, rumah dome.

\section{Positioning}

Di dalam ranah desa wisata sleman, rumah dome merupakan yang paling unik. Tidak hanya dni sleman tetapi juga Yogyakrta bahkan di Indonesia. Keunikan inilah yang semestinya dimanfaatkan sebaik-baiknya oleh pengelola. Ini adalah kekuatan yang sangat kuat untuk mengalahkan para pesainya di antara desa-desa wisata Sleman, bahkan di Yogyakarta.

Menurut pengelola, Mas Sakiran, Rumah Dome sering dikunjungi para wisatawan baik domestik maupun mancanegara. Yang menjadi daya tarik dari rumah ini adalah bentuknya. Di Indonesia hanya terdapat di Yogyakarta. Sejarah terbentuknya juga menjadi daya tarik tersendiri. "Mereka ke sini pingin melihat bentuknya. Kemudian yang kita jual adalah ceritanya," terang Sakiran. Para penduduk menempati rumah ini karena tempat tinggal mereka tanahnya amblas ketika terjadi gempa sekitar enam tahun yang lalu.

\section{Analisis SWOT}

Terlepas dari betapa unik desa wisata rumah dome, objek wisata ini masih menyimpan beberapa kelemahan. Berikut penjabaran beberapa poin terkait analisis SWOT desa wisata rumah dome:

\begin{tabular}{|c|c|}
\hline $\begin{array}{l}\text { Strengths } \\
\text { - Rumah unik } \\
\text { - Satu-satunya di Yogyakarta } \\
\text { - Akses mudah, berada di arah } \\
\text { Prambanan dan Ratu Boko dan } \\
\text { dekat jalan utama Yogyakarta- } \\
\text { Gunungkidul } \\
\text { - Dekat dengan objek wisata pantai } \\
\text { (Gunung Kidul) }\end{array}$ & $\begin{array}{l}\text { Weaknesses } \\
\text { - Mulai tidak terawat (perawatan } \\
\text { buruk) } \\
\text { - Warga membangun bangunan } \\
\text { permanen tambahan di belakang } \\
\text { rumah dome } \\
\text { - SDM kurang memadai } \\
\text { - Penanaman pohon di sekitar rumah } \\
\text { yang mengakibatkan rumah dome tak } \\
\text { terlihat } \\
\text { - Kurangnya promosi } \\
\text { - Kurangnya variasi atraksi wisata }\end{array}$ \\
\hline $\begin{array}{l}\text { Opportunities } \\
\text { - Menjadi bagian dari paket wisata di } \\
\text { Sleman bahkan Yogyakarta } \\
\text { - Masih banyak potensi yang bisa } \\
\text { dikembangkan } \\
\text { - Bermacam-macam konsep } \\
\text { pengembagan bisa dilakukan } \\
\text { seperti edu-tourism, nostalgia } \\
\text { tourism dll }\end{array}$ & $\begin{array}{l}\text { Threats } \\
\text { - Banyaknya desa wisata di Sleman } \\
\text { dan Yogyakarta secara umum } \\
\text { - Munculnya wisata-wisata } \\
\text { edukasi/rekreasi di sekitar rumah } \\
\text { dome, e.g kids fun dll }\end{array}$ \\
\hline
\end{tabular}




\section{National Conference of Creative Industry: Sustainable Tourism Industry for Economic Development}

Universitas Bunda Mulia, Jakarta, 5-6 September 2018

Dari SWOT Matrix di atas, bisa diketahui jika memang rumah dome memiliki posisi (positioning) yang menguntungkan dan berkesempatan lebar menjadi objek wisata unggulan di Sleman dan Yogyakarta. Salah satu paket menarik yang bisa ditawarkan adalah tiga wisata sekaligus yaitu heritage tourism - edutourism - natural tourism. Heritage tourism adalah candi prambanan dan ratu boko, edutourism adalah rumah dome, dan natural tourism adalah pantai-pantai di Gunungkidul. Sehingga sekali lagi perlu dilakukan kerjasama yang baik dengan pihak biro travel/agen perjalan untuk menge-drop pengunjung di desa wisata rumah dome dengan penawaran paket di atas.

\section{KESIMPULAN DAN IMPLIKASI}

\section{Kesimpulan}

Kurangnya promosi desa wisata rumah dome terjadi bukan karena keterbatasan anggaran akan tetapi dana yang diperoleh (pernah mendapat 100 Juta dari PNPM Mandiri) lebih digunakan untuk membeli wahana-wahana permainan. Sementara masyarakat lokal sendiri belum paham keberadaan desa wisata di rumah dome. Hal inilah yang menyebabkan kunjungan wisatawan di desa wisata ini masih rendah.

Selain isu di atas, rumah dome masih sangat potensial untuk dikembangkan menjadi "perantara" yang strategis antara heritage tourism (candi-candi) dengan natural tourism (pantai-pantai). Hal ini mengingat lokasi rumah dome yang berada di antara kedua jenis wisata yaitu candi prambanan dan ratu book dengan pantai-pantai di Gunung Kidul.

\section{Saran}

Diperlukan berbagai strategi kreatif untuk meningkatkan kunjungan wisatawan di desa wisata Kabupaten Sleman. Diantaranya melalui even-even yang secara tidak langsung memperkenalkan daya tarik desa wisata kepada wisatawan nusantara dan berbagai aktivitas yang berada di dalamnya. Yang tak kalah penting strategi media, perlu untuk mempublikasikan media cetak, koran, brosur, leaflet, booklet, media elektronik TV, radio, bioskop, dan media-media online.

Selain strategi promosi dengan memperbanyak media pemasaran di atas, rumah dome masih sangat strategis sebagai tempat istirahat bagi wisatwan yang berkunjung ke Prambanan dan Ratu Boko. Lokasinya yang tidak terlalu bahkan satu arah dengan Ratu Boko inilah yang memungkinkan rumah dome untuk dijadikan tempat peristirahatan sementara bagi para wisatawan. Sehingga perlu dilakukan kerjasama antara pengelola dengan pihat travel. Kerjasama ini urgen untuk dilakukan mengingat tidak semua wisatawan yang berkunjung ke Prambanan dan Ratu Boko namum mereka tidak mengetahui keberadaan rumah dome.

\section{DAFTAR PUSTAKA}

Angipora, P.M. (2002). Dasar-dasar Pemasaran. Edisi Kedua. Jakarta: PT. Raja Grafindo Persada 


\section{National Conference of Creative Industry: Sustainable Tourism Industry for Economic Development}

Universitas Bunda Mulia, Jakarta, 5-6 September 2018

ISSN No: 2622-7436

Inskeep, E. (1991). Tourism Planning: AnIntegratedandSustainable Development Approach. New York: Lawson and Bovy

Kotler, P. (2005). Manajemen Pemasaran. Jakarta: PT. IndeksKelompok Gramedia

Muliawan, H.(2008).Pengembangan Pariwisata Berbasis Masyarakat Konsep dan Implementasi. tanpa kota: tanpa penerbit.

Nasution, S. (1988). Metode Penelitian Naturalistik Kualitatif. Bandung: Tarsito

Nuryanti, W. (1993). Concept, Perspective, and Challenges. Dalam: Nuryanti, W. (editor-inchief). 1993. UNIVERSAL TOURISM: ENRICHING OR DEGRADING CULTURE?, Proceedings on the International Conference on Cultural Tourism. Yogyakarta: Gadjah Mada University Press

Tjiptono, F. (1997). Strategi Pemasaran. Edisi Kedua. Yogyakarta: Andi Offset. 